\title{
Intersubjective principle of innovative development of regions management
}

\author{
Tatiana Moiseeva, and Yuri Myatishkin \\ Samara Federal Research Scientific Center RAS, Institute for the Control of Complex Systems RAS, \\ 443020 Sadovaya Str., 61, Samara, Russia
}

\begin{abstract}
Sustainable development of regions should ultimately lead to the renewal and expansion of consumer goods. Their quality influence the growth of living standard. In modern society, the main emphasis is placed on the emergence of innovations in the production process. In this regard, innovative development is seen as a means to make profit. At the same time, the connection with the broad interests of consumers is lost. Attention is turned to the increasing of the ability of goods to perform the purpose they were created for. Comprehensive formulation of tasks for business on the part of consumers should become the primary source for the goods design and the direction of technological development of production. In this regard, a new understanding of innovative idea as a result of the joint resolution of a problem situation by actors who are aware of themselves within the problem situation is proposed. The formation of territorial consumer cooperatives of the new type as a means of realizing a subject-oriented approach to innovative development is proposed.
\end{abstract}

\section{Introduction}

Finding the ways of the balanced improvement of economic, social and environmental aspects of the development of the regions, which form the basis of their sustainable development is the urgent task of our time. Decisions made in this area have predominantly bureaucratic character because they mostly reflect the image of regions development that was emerged in the minds of representatives of the administrative and bureaucratic authorities.

Their action to improve the financial and social situation of the regions residents are mainly carried out in accordance with their own vision, orders of higher authorities and available demand of the market. Citizens' opinion is taken into account to a large extent rather formally. As a result, budget funds are often used to create ineffective or even unnecessary objects, which, on the contrary, rather reduce the quality of citizens life.

The way to determine what is really useful for citizens and society as a whole is of interest not only from improving the quality of consumption of citizens point of view. It is also of interest from the emergence of new objects of profitable investment for business and the growth of the tax base on this basis in the interests of the state.

New understanding of sustainable development of the region based on new understanding of innovation, as a result of collective search for a way out of problem situations of ordinary people inhabiting the region, is proposed in this paper. 
The widespread understanding of innovation is more consistent with its definition launched into scientific circulation by the Austrian and American economist Josef Alois Schumpeter. He defined innovation as a phenomenon that characterized the emergence of something new, previously unknown, increasing the efficiency of the current system [1]. Entrepreneurship was initially defined as the target of innovation. This understanding of innovation, which was formed at the beginning of the twentieth century, mainly associated with the economic sphere. It had a significant impact on the conceptual innovation toolkit, which is actively inculcated today.

Most of the researchers studying the problem areas of innovation interpret "innovation" as a product that did not exist before, or a process aimed at producing a given product. Therefore, innovation is predominantly associated with scientific and technical inventions or profitable products that can be used in the market, or technological innovation in the structure of production that turns economic profit.

Such understanding of innovations and their role in the economy has exhausted itself from our point of view. Innovative activity should extend beyond design offices and scientific institutes, approaching real problems of ordinary people. Thus, new social tools that allow this interaction would be created.

\section{Materials and Methods}

The material for this research is social and economic relations arising in the process of innovation emergence. The research method is theoretical analysis and synthesis based on formal logic.

\section{Results and Discussion}

\subsection{Development of goods as a means of resolving problematic situations of consumers}

Understanding of innovation as a result of actors' problem situations solving was presented in the theory of intersubjective management, which was launched one decade ago [6-9]. This new theory offers a methodological basis for managing the problem situations solution by a group of actors.

The main idea of the theory is that once in a problem situation, active people (actors) begin to look for other participants in the situation, on a voluntary basis form self-organized communities with them, in the course of communications build an intersubjective ontological model of the situation and jointly seek a solution $[10,11]$. They involve into this process competent specialists, representatives of economic organizations, as well as local authorities. The found solution is the innovation. It is the result of the actors' understanding of the problem situation, which formulates the idea of some innovation, with the help of which it could be regulated and which will create additional value for the actors $[12,13]$.

Any innovation is aimed at solving certain problems (tasks) of the consumer. The difference between an innovative product and an existing one lies in the fact that its user solves his problems in a completely different way than other people who find themselves in a similar situation. The value of innovation is determined by how well a new product solves its user's problems. This value ultimately gives rise to the willingness of the future consumer to invest resources in its creation or in the purchase of any ready-made product. 
The process of emerging new products characterizes innovative development. To intensify it, it is necessary to manage the process of solving problem situations. Therefore, it is necessary to study and generalize the present and future problems of citizens and society as a whole. It is advisable to organize their systematic solution after understanding the nature of the origin of problems in the communities of the participants who solve the problem. Only after this the true needs of citizens will become clearer, and it is expedient to satisfy them.

Today we see a gap between the true needs of citizens and what is provided by production. There is a strong imbalance of the proposed means of solving consumer problems with an emphasis on technical properties. The context of the produced goods use is little considered. The new products themselves create many problems (social, environmental, material, etc.), which in the process of the product original purpose improving drop out of the field of consideration of manufacturers.

Today this problem has become more acute. New means of production have become more powerful, stronger, more productive, and their range has expanded significantly. Therefore, the use of modern goods more and more affects the interests of people around. It is getting closer, noisier, there are more emissions and garbage that pollute the atmosphere, etc. Violation of the citizens' interests is no longer carried out manually, but in a mechanized way, and this significantly aggravates the problems. Technical means of greater power become a source of man-made accidents of much more destructive nature than the breakdown of simple hand devices that dominated in everyday life among our ancestors.

Today, requirements for new industrial goods are formed on the basis of marketing research. Designers find certain technical and technological solutions based on modern scientific research. Further, the documentation is transferred to production, which is a very complex technological process, as a rule. Many modern goods have become so complicated that it was very difficult for the average man in everyday life to understand all their properties.

The development of production increases the gap between the levels of competence of producers and consumers. Today the buyer finds himself in a position where he is not able to adequately assess the provided consumer opportunities of the offered goods. He is more and more forced to rely on the brand than on information about the actual physical properties of the purchased goods. Having received the purchased products at their disposal, its user, being insufficiently educated, cannot use the received product to the full. Thus, he buys properties that are excessive for himself, that is, unnecessary.

The list of technogenic problems is replenished with social and psychological problems arising from the fact that citizens have weakened their interest in each other, and, consequently, the need to negotiate and take into account the interests of the people around them. The emergence of demand on the basis of solving the problems caused by new consumption is not a positive phenomenon, since it is wiser to avoid problems than to correct the consequences.

\subsection{Development of local self-management}

To implement the management of problem situations, regular negotiations of citizens are required to reach agreement on the items and methods of consumption in territorial communities. It is proposed to organize regional consumer cooperatives, and to hold discussions on consumer topics for their joint purchases within these organizations. In the same communities, you can implement a system for improving consumer literacy.

Collective discussion of consumer goals contributes to improving the quality of purchases through meaningful preparation of requirements for supplied goods. Therefore, in local consumer communities, it is advisable to carry out pre-design work on the formation of 
technical specifications for manufacturers. Thus, it is possible to bring innovative activities, the main element of which is joint decision-making, to a new level of development.

It is necessary to form a new type of consumer cooperation, which, in addition to joint purchases, will include a developed system of joint decision-making by community members to agree on items and methods of consumption. These resilient neighborhood communities (the modern equivalent of communities) should be a source of new demand. There will be rising shared consumption.

The means of collective consumption should not represent selected goods, but commodityconsumer systems. Such systems should include, in addition to material objects, the rules for their alternate or joint use, methods of social interaction, algorithms for the operation of technical systems, etc.

These complex products should be born within the framework of solving joint problem situations (consumer problems). Problems' solving should be carried out within groups by methods of intersubjective management. The main motive for interaction should be neither earnings (this is not a commercial organization), nor submission to violence (this is an institution of civil society). It should be the solution of certain problem situation. This approach will ensure the most accurate identification of consumer interests, which will be taken into account in the process of assignments formation for work performers and manufacturers of goods.

The establishing of such communities requires an investment of resources in the system which serves the interaction of participants. All parts of social interaction should be in the role of contributors. The first part is citizens (it promises them an increase in the quality of life); the second is business (it will receive a new form of marketing) and, finally, it is government (for which it is important to increase investment activity, since this ensures an increase in the tax base).

Such activity on making an agreed decision regarding the solution of a problem situation should be classified as pre-innovation. Therefore, we propose to introduce a new term "preinnovation", denoting consumer innovation which is a description of an imaginary complex product that does not yet exist, but some of its contours are visible, or there is a part of a prototype. It should be sufficient for entrepreneurs to invest in creating a startup. Preinnovation activity consists of creating an image of a desired product (but not a ready-made solution) that can support the willingness of its future consumers to make the initial investment so that it will eventually be created by entrepreneurs or consumers themselves and solve their problem.

Similar activities exist today. Citizens themselves create many tools for personal use. They have no prospects for commercial use for their authors. These are all kinds of crafts, buildings and so on. A special place is occupied by software, which becomes a product with "open source". This activity arises from the lack of readiness or the ability to buy a product identical to the one created independently. Often innovations are created. They solve problem situations of local importance.

Users exchange experience and information, uniting in self-organized communities, improving not only the original product being promoted to the market, but also the technologies for its creation, obeying the solution of the main task, which is formulated as improving of their own user practice.

The advancement and popularization of the concept of "open innovation" today is facilitated by theoretical developments of Eric von Hippel, H.W. Chesbrough $[2,3,4,5]$ and others. The essence of the concept is that companies that develop new products and technologies should use not only their own internal corporate scientific developments, but also actively introduce innovation, competencies and creativity from the external environment by referring to user innovation that is generally unrelated to scientific research and its applications [Chesbrough, 2003]. 
As a result of pre-innovation activities, it is proposed to form a consumer request that is similar in meaning to the technical specifications for the manufacture of a product, but is not fully looks like it. This is not a precise task for the executor of work or supplier, since, on the one hand, the consumer does not know all the production possibilities. On the other hand, the manufacturer assumes the risks associated with the willingness of other people to buy new products being created and must take into account the interests of wider range of consumers.

Pre-innovation is a product of the labor activity of people and their financial investments; therefore, it is a commodity itself. The right to this commodity belongs to the participants searching for a method of the problem situation solving. Pre-innovation can be compared to the first marketing stage of the product (product by design), but it is a more perfect product.

\section{Conclusions}

1. The proposed subject-oriented approach to innovative development will not only meet the needs of people, but also bring the work on sustainable development of regions to a new scientific and methodological level. This will require changes not only in the relations between society and business, but also in the relations between society and authorities.

2. The proposed change in the format of the economy will require the development of the skills of interpersonal interaction of ordinary citizens. It will be aimed at taking into account a wide range of interests of participants in group and public interaction. This will contribute to the humanization of society.

3. It is obvious that the outlined approach to the organization of the economy shifts serial production towards less mass and higher quality. As a result, significant distinctive features of new consumer goods (in comparison with analogues) will appear. These are expensive goods. It means that they must be used for a longer time and more intensively, so that the available purchasing power of people would be sufficient for the previous product mix. In addition to accelerating technological development, it will help to reduce in revolutionary way the anthropogenic stress on the natural environment.

4. Intersubjective decision-making according to the method of solving a joint problem should include all aspects of the consumption of new goods: from physical properties and rules of their use to the method of disposal. This will allow the best possible solution to the current consumer problem and to avoid problems in the future as much as possible.

5. Changing the way of consumption will create a natural protection of domestic markets due to the uniqueness of the local economy, which requires special (other) technologies to solve its local economic problems. However, on this basis, it is possible to predict the problem of a shortage of necessary goods, which will have to be constantly solved at each new historical stage in its own way.

6. Involving a wide number of participants in overcoming of a common problem provides the organizers of its solution with a large amount of information about the essence of the problem itself and about possible methods of its overcoming. Official assistance in the citizens problems solving with the fund-raising will provide them with additional opportunities to influence people and thereby reduce the need for the use of violence by the state authorities. Thus, the nature of public administration will change towards greater democratization. 


\section{Acknowledgements}

The article was prepared according to the plan of research work of Samara Federal Research Scientific Center RAS, Institute for the Control of Complex Systems RAS "Development and research of methods and tools for analytical design, computer representation of knowledge, computational algorithms and multi-agent technologies in optimization problems of complex systems management processes", No. AAAA-A19119030190053-2.

\section{References}

1. J. Schumpeter, History of Economic Analysis (1963).

2. H. Chesbrough, Open Innovation: The New Imperative for Creating and Profiting from Technology (2003).

3. H. Chesbrough, Open Business Models. How to Thrive in the New Innovation Landscape (2006).

4. E. von Hippel, Jeroen de Jong, Open, Distributed and User-Centered: Towards a Paradigm Shift in Innovation Policy (2010).

5. G. Mulgan, S. Tuckers, R. Ali, B. Sanders, Social Innovation: What It Is, Why It Matters and How It Can be Accelerated (2007).

6. Vladimir A. Vittikh, Group Decision and Negotiation. 24(1), 67 (2015)

7. Vladimir A. Vittikh, Group Decision and Negotiation, 24(5), 825 (2015)

8. Vladimir A. Vittikh, Group Decision and Negotiation, 24(6), 949 (2015)

9. Vladimir A. Vittikh, Int. J. Management Concepts and Philosophy, 9(2), 63 (2016)

10. T.V. Moiseeva, N.Yu. Polyaeva, Proc. 8th Scientific Conference on Information Technologies for Intelligent Decision Making Support (2020).

11. T.V. Moiseeva, Proc. XXI Int. Conf. "Complex Systems: Control and Modeling Problems" (CSCMP 2019). IEEE Xplore, 765 (2019).

12. T.V. Moiseeva, S.V. Smirnov, Studies in Systems, Decision and Control, 199, 15 (2019)

13. T.V. Moiseeva, Proceeding of the International Science and Technology Conference "FarEastCon 2019", 267 (2019) 